\title{
Evaluating gas chromatography with a halogen-specific detector for the determination of disinfection by-products in drinking water
}

\author{
Anna Andersson ${ }^{1}$ - Muhammad Jamshaid Ashiq ${ }^{1}$ - Mohammad Shoeb ${ }^{1,2} \cdot$ Susanne Karlsson $^{1}$ • David Bastviken ${ }^{1}$. \\ Henrik Kylin ${ }^{1,3}$ (D)
}

Received: 19 October 2017 / Accepted: 29 January 2018 / Published online: 28 February 2018

(C) The Author(s) 2018. This article is an open access publication

\begin{abstract}
The occurrence of disinfection by-products (DBPs) in drinking water has become an issue of concern during the past decades. The DBPs pose health risks and are suspected to cause various cancer forms, be genotoxic, and have negative developmental effects. The vast chemical diversity of DBPs makes comprehensive monitoring challenging. Only few of the DBPs are regulated and included in analytical protocols. In this study, a method for simultaneous measurement of 20 DBPs from five different structural classes (both regulated and non-regulated) was investigated and further developed for 11 DBPs using solid-phase extraction and gas chromatography coupled with a halogen-specific detector (XSD). The XSD was highly selective towards halogenated DBPs, providing chromatograms with little noise. The method allowed detection down to $0.05 \mu \mathrm{g} \mathrm{L}{ }^{-1}$ and showed promising results for the simultaneous determination of a range of neutral DBP classes. Compounds from two classes of emerging DBPs, more cytotoxic than the "traditional" regulated DBPs, were successfully determined using this method. However, haloacetic acids (HAAs) should be analyzed separately as some HAA methyl esters may degrade giving false positives of trihalomethanes (THMs). The method was tested on real water samples from two municipal waterworks where the target DBP concentrations were found below the regulatory limits of Sweden.
\end{abstract}

Keywords Drinking water $\cdot$ Disinfection by-products $\cdot$ Trihalomethanes $\cdot$ Haloacetic acids $\cdot$ Haloacetonitriles $\cdot$ Halogen-specific detector

\section{Introduction}

Disinfection to kill harmful pathogens is essential to produce safe drinking water, particularly from surface water sources. Disinfection is often accomplished, by using strong oxidants,

Responsible editor: Hongwen Sun

Electronic supplementary material The online version of this article (https://doi.org/10.1007/s11356-018-1419-2) contains supplementary material, which is available to authorized users.

Henrik Kylin

henrik.kylin@liu.se

1 Department of Thematic Studies-Environmental Change, Linköping University, SE-581 83 Linköping, Sweden

2 Present address: Department of Chemistry, University of Dhaka, Dhaka, Bangladesh

3 Research Unit: Environmental Sciences and Management, North-West University, Potchefstroom, South Africa such as chlorine, chloramines, chlorine dioxide, or ozone. The chemical disinfectants kill pathogens efficiently, but they also produce unwanted disinfection by-products (DBPs) when reacting with natural organic matter (NOM), anthropogenic contaminants, bromide, or iodide present in the source water (Richardson and Postigo 2015). These DBPs may in themselves be harmful, e.g., having carcinogenic (Cantor 1997; IARC 1995), mutagenic (Cemeli et al. 2006), or genotoxic (IARC 1999) properties. Epidemiological studies suggest increased risk of bladder cancer associated with DBP exposure (Villanueva et al. 2015). Different routes of exposure to DBPs, e.g., drinking, showering, bathing, laundry, and cooking, have been identified, and in one study, the bladder cancer risk was more pronounced by bathing, showering, or swimming in, than drinking the water (Villanueva et al. 2007).

More than 600 DBPs have been identified, but they account for less than $50 \%$ of the total organic halogen (TOX) formed (Richardson and Postigo 2015). Among the DBPs, trihalomethanes (THMs) and haloacetic acids (HAAs) have received most attention, and the levels of these DBPs in 
drinking water are regulated in many countries (Goslan et al. 2009). Most OECD countries have introduced guidelines to control DBPs and minimize consumer's exposure while maintaining adequate disinfection and control of targeted pathogens. However, these guidelines are based on limited knowledge on the chemical diversity of DBPs. In the USA, THMs, HAAs, and bromate are regulated with maximum contaminant limits (MCL) of 80, 60, and $10 \mu \mathrm{g} \mathrm{L}^{-1}$, respectively (EPA 2010). In the European Union, the total THMs and bromate $\left(\mathrm{BrO}_{3}{ }^{-}\right)$ are regulated at 100 and $10 \mu \mathrm{g} \mathrm{L}^{-1}$, respectively (EU 1998). Most previous research has concerned the regulated DBPs, but recently, the interest in unregulated DBPs has increased markedly (Adams et al. 2005; Richardson and Postigo 2015). These include, e.g., haloketones (HKs) and groups of DBPs specifically referred to as emerging DBPs, including haloacetonitriles (HANs), halonitromethanes (HNMs), haloamides, halofuranones, haloacetaldehydes, nitrosamines, halobenzoquinones, iodo-trihalomethanes, and iodo-acids (Richardson and Postigo 2015). These compounds are also formed during disinfection along with THMs and HAAs but typically at lower concentrations (Krasner et al. 2006; Richardson et al. 2007). In spite of the lower concentrations, these unregulated DBPs may represent a larger public health concern, as most of them are more toxic than the regulated DBPs (Bull and Robinson 1986; Plewa et al. 2008; Richardson et al. 2007). In drinking water samples from Spain, France, and the UK, unregulated nitrogen containing DBPs (N-DBPs) accounted for $>90 \%$ of the $\mathrm{CHO}$ cell cytotoxicity (Plewa et al. 2017); N-DBPs, and haloacetonitriles in particular, represented the forcing agents for cytotoxicity in these water samples. This calls for an adaption of monitoring methods that include DBPs that are of largest public health concern.

During the past three decades, several methods to determine DBPs from different classes have been published, including both GC and LC methods (Chinn et al. 2007; Ding and Zhang 2009; Nikolaou et al. 2002; Pavón et al. 2008; Richardson 2011; Richardson and Ternes 2005; Zhao et al. 2010). A recent review on determination of nitrogenous DBPs concluded that the majority of available methods can determine one or two classes of DBPs only, and called for a development of new methods that can measure several DBP classes simultaneously to improve monitoring (Ding and Chu 2017).

DBPs occur in drinking water at low $\left(n \mathrm{~L}^{-1}-\mu \mathrm{g} \mathrm{L}^{-1}\right)$ concentrations (Richardson et al. 2007), and the limit of detection (LOD) of the used methods is therefore critical. The LOD depends on both the sample volume and the extraction procedures, among other factors. Differences in physical and chemical properties between different classes of DBPs may make it difficult to extract all target DBPs with a single extraction procedure. There are different methods available for extraction of DBPs. Both liquidliquid extraction (LLE) (Golfinopoulos and Nikolaou 2005) and solid-phase extraction (SPE) (Buszewski and Szultka 2012; Dittmar et al. 2008; Qian et al. 2015) have been frequently used, but may need fine tuning for specific compound classes. Advantages of SPE over LLE include less solvent consumption, salt free extracts, and that SPE methods can be automated (Buszewski and Szultka 2012).

The volatile DBPs, e.g., THMs, HANs, and HKs, have been quantified using GC-MS (Richardson 2010) or GC with electron capture detection (ECD) (Chinn et al. 2007; Hodgeson et al. 1990; Tominaga and Mídio 2003). For the determination of more polar DBPs with ionizable functional groups (e.g., HAAs), derivatization is necessary prior to separation with GC. The most commonly used derivatizing reagents are diazomethane and acidic methanol (Hodgeson et al. 1995; Sarrión et al. 2000; Xie 2001). The ECD is selective for compounds containing electronegative functions. These include not only halogens but also compounds containing, e.g., nitrogen or sulfur. Further, large amounts of hydrocarbons from the matrix may give rise to negative peaks and noise (Lovelock 1958). Interferences from non-halogenated and co-eluting compounds is therefore a limitation for the analysis of halogenated organic compounds, which is directly associated with the detector.

To address the need of higher selectivity and specificity than given by an ECD, a halogen-specific detector (XSD) was developed that is selective towards halogenated compounds only (OI Analytical 2017). This detector has been used to determine chlorinated fatty acids in biological samples where neither GC-ECD nor GC-MS gave a sufficient chlorine/hydrocarbon selectivity (Nilsson 2004). In the XSD, the GC effluent undergoes oxidative pyrolysis under which halogenated compounds are converted to oxidation products and free halogens. The free halogens react with the alkali-sensitized surface of the cathode, which yields an increased thermionic emission that can be measured (Nilsson et al. 2001; OI Analytical 2017). The XSD has successfully been applied for the analysis of chlorinated compounds such as pesticides (Brown et al. 2011) and halogenated fatty acids (Nilsson et al. 2001; Zhuang et al. 2005).

Within a larger project in which unknown DBPs are identified with ultra-high-resolution spectroscopic methods, we also aim to develop suitable methods for routine monitoring. Given its high selectivity and specificity for halogens, the GCXSD was expected to give the possibility to detect halogenated DBPs that are not detected with other routine monitoring methods. Here, we present results from a study to investigate the potential of GC-XSD methods for simultaneous 
monitoring of a range of DBPs of interest to Swedish waterworks, including THMs, HAAs, HANs, HKs, and HNMs.

\section{Experimental}

\section{Chemicals}

LC-MS grade methanol $(\mathrm{MeOH})$ and sulfuric acid 95-97\% Merck were acquired from VWR (Spånga, Sweden). Methyl tertiary butyl ether (MTBE) $98 \%$, sodium sulfate $\left(\mathrm{Na}_{2} \mathrm{SO}_{4}\right)$, and sodium bicarbonate $\left(\mathrm{NaHCO}_{3}\right)$ were acquired from Sigma-Aldrich (Stockholm, Sweden) and ethanol 96\% from Solveco (Rosersberg, Sweden). The selected compounds including their class, chemical name, and abbreviation are presented in Table 1.

\section{Standard solutions}

Standards of THMs (bromoform, chloroform, bromodi chloromethane, dibromochloromethane) and other neutral DBPs, viz. HANs (dichloroacetonitrile, dibromoacetonitrile, bromochloroacetonitrile, trichloroacetonitrile), HKs (1,1dichloro-2-propanone and 1,1,1-trichloro-2-propanone) and a HNM (trichloronitromethane), and HAAs (monochloroacetic acid, monobromoacetic acid, dichloroacetic acid, dibromoacetic acid, trichloroacetic acid, bromochloroacetic acid, bromodichlo roacetic acid, chlorodibromoacetic acid and tribromoacetic acid) were from Restek, acquired from Teknolab Sorbent (Kungsbacka, Sweden). Additional standards of 1,2dibromopropane $(97 \%)$ and 1-chlorodecane were acquired from Sigma-Aldrich (Stockholm, Sweden).

Stock solutions in methanol containing $0.2 \mu \mathrm{g} \mathrm{L}^{-1}$ (stock solution 1, Table S1), $0.02 \mu \mathrm{g} \mu \mathrm{L}^{-1}$ (stock solution 2), and $0.002 \mu \mathrm{g} \mu \mathrm{L}^{-1}$ (stock solution 3 ) were prepared for every THM, HAN, HK, HNM, and HAA (see Table S1 in supplementary information for details). The stock solutions were added to samples of Milli-Q water for calibration, as well as to MtBE for direct GC-XSD determination. The surrogate standard 1,2-dibromopropane was prepared in methanol and the recovery standard 1-chlorodecane was prepared in MTBE.

\section{SPE procedure}

SPE was performed with Bond Elute PPL (modified styrene divinylbenzene polymer, $200 \mathrm{mg}$ in 3-mL cartridges, Agilent Technologies, acquired from Scantec, Partille, Sweden) using a vacuum manifold (10 port, Sorbent, Göteborg, Sweden).

\section{Neutral DBPs (THMs, HANs, HKs, HNMs)}

To test the method capacity to detect the selected target DBPs, Milli-Q water ( $1 \mathrm{~L})$ was spiked with standard mixes to a concentration of $20 \mu \mathrm{g} \mathrm{L}^{-1}$ of each compound and the $\mathrm{pH}$ was
Table 1 Summary of selected compounds along with their class, compound name, and abbreviation

\begin{tabular}{lll}
\hline Compound class & Compound name & Abbreviation \\
\hline Trihalomethanes (THMs) & Tribromomethane (bromoform) & TBM \\
& Trichloromethane (chloroform) & TCM \\
& Bromodichloromethane & BDCM \\
& Dibromochloromethane & DBCM \\
Haloacetonitriles (HANs) & Bromochloroacetonitrile & BCAN \\
& Dibromoacetonitrile & DBAN \\
Haloketones (HKs) & Dichloroacetonitrile & DCAN \\
Halonitromethanes (HNMs) & Trichloroacetonitrile & TCAN \\
Haloacetic acids (HAAs) & 1,1 -Dichloro-2-propanone & DCP \\
& 1,1,1-Trichloro-2-propanone & TCP \\
& Trichloronitromethane (chloropicrin) & TCNM \\
& Monochloroacetic acid & MCAA \\
& Monobromoacetic acid & MBAA \\
& Dichloroacetic acid & DCAA \\
& Dibromoacetic acid & DBAA \\
& Trichloroacetic acid & TCAA \\
& Bromochloroacetic acid & BCAA \\
& Bromodichloroacetic acid & BDCAA \\
& Chlorodibromoacetic acid & CDBAA \\
& Tribromoacetic acid & TBAA \\
\hline
\end{tabular}


lowered to $\approx 2$ with sulfuric acid $\left(1 \mathrm{~mol} \mathrm{~L}^{-1}\right)$. The surrogate standard 1,2-dibromopropane ( $50 \mu$ g, i.e., $25 \mu \mathrm{L}$ of stock solution 1) was added before extraction. The SPE cartridges were activated by passing $\mathrm{MeOH}(2 \times 3 \mathrm{~mL})$ through the cartridge followed by acidified Milli-Q water $(3 \mathrm{~mL}, \mathrm{pH} \approx 2)$. The cartridges were placed on a manifold. The water samples and the cartridges were connected via PTFE tubes (ID $2 \mathrm{~mm}$ ) with one end attached to the cartridge via an adaptor and the other end inserted in the glass bottles containing the water samples. The glass bottles were placed $1.5 \mathrm{~m}$ above the cartridges for the extraction. The water samples were fed to the cartridges by gravity at a flow rate of not more than $10 \mathrm{~mL} \mathrm{~min}{ }^{-1}$. After extraction, vacuum was gently applied for $30 \mathrm{~s}$ to remove excess water. $\mathrm{MeOH}(100 \mu \mathrm{L})$ was added to the cartridges, after which the analytes were eluted with MtBE $(2 \mathrm{~mL})$ and the extracts were collected in 4-mL glass vials. Fifty microgram recovery standard $(10 \mu \mathrm{L}$ stock 1 in Table S1; 1-chlorodecane) was added to each extract, and $1 \mathrm{~mL}$ was transferred to auto sampler GC vials for GC-XSD analysis (see Chart S1 in supplementary information for a schematic overview of the method). The remaining extracts were stored at $-20^{\circ} \mathrm{C}$.

\section{Haloacetic acids}

The $\mathrm{pH}$ of Milli-Q water $(50 \mathrm{~mL})$ was adjusted to $\approx 0.5$ with sulfuric acid $\left(1 \mathrm{~mol} \mathrm{~L}^{-1}\right)$ and spiked with $20 \mu \mathrm{g} \mathrm{L}^{-1} \mathrm{HAA}$ mix standard solution $(100 \mu \mathrm{L}$ of the HAA mix standard stock solution 1, see Table S1). SPE was performed as described above after which the analytes were eluted with $\mathrm{MeOH}(1 \mathrm{~mL})$ and MtBE ( $2 \mathrm{~mL}$ ). EPA method 552.3 (Domino et al. 2003) was used for esterification. Briefly, the extracts were transferred to $15-\mathrm{mL}$ glass tubes and acidic methanol $(2 \mathrm{~mL})$ was added. To initiate the methylation reaction the glass tubes, with Teflon-lined screw caps were placed in a water bath (50 $\left.\pm 2{ }^{\circ} \mathrm{C}, 2 \mathrm{~h} \pm 10 \mathrm{~min}\right)$. After methylation, sodium sulfate solution $\left(5 \mathrm{~mL}, 150 \mathrm{~g} \mathrm{~L}^{-1}\right)$ was added followed by vortexing, after which the test tube was left standing until the phases were clearly separated. The upper phase, containing the esters, was transferred to a $10-\mathrm{mL}$ test tube. Saturated sodium bicarbonate solution $(1 \mathrm{~mL})$ was added to raise the $\mathrm{pH}$ of the acidic extracts to a neutral $\mathrm{pH}$. After vortexing again, the tubes were left for phase separation, and the upper layers containing esters were transferred to 4-mL glass storage vials. Of the extracts, $1 \mathrm{~mL}$ aliquots were transferred to $\mathrm{GC}$ vials for GC-XSD analysis (see Chart S2 in supplementary information for a schematic overview of the method). The remaining extracts were stored at $-20^{\circ} \mathrm{C}$.

\section{Survey of waterworks and drinking water}

After the above tests, the described method for neutral DBPs was used to determine DBPs in real drinking water samples collected from two waterworks, Berggården in Linköping municipality and Borg in Norrköping municipality, Sweden. Samples $(1 \mathrm{~L})$ were collected at three different sites before and three sites after disinfection. The waterworks use the same surface water source, Motala ström, Berggården, approximately $50 \mathrm{~km}$ upstream of Borg, but different disinfection systems (Figs. S1 and S2). Briefly, Berggården used UV followed by hypochlorite for disinfection. At Borg, disinfection was performed using chloramination, a supposedly milder disinfectant. For further details, see the supplementary information.

Table 2 Retention times for studied neutral DBPs at the optimized temperature program, calibration range for each compound, correlation coefficients for calibration curves, extraction recoveries with standard deviations, and estimated limits of quantifications (LOQ)

\begin{tabular}{|c|c|c|c|c|c|c|}
\hline Compound & $\begin{array}{l}\text { Retention } \\
\text { time (min) }\end{array}$ & $\begin{array}{l}\text { Calibration } \\
\text { range }\left(\mu \mathrm{g} \mathrm{L}^{-1}\right)\end{array}$ & $\begin{array}{l}\text { Correlation } \\
\text { coefficient }\left(R^{2}\right)\end{array}$ & $\begin{array}{l}\text { Mean recovery } \\
(\%)\end{array}$ & $\begin{array}{l}\text { Standard } \\
\text { deviation }\end{array}$ & $\begin{array}{l}\text { Estimated LOQ } \\
\left(\mu \mathrm{g} \mathrm{L}^{-1}\right)\end{array}$ \\
\hline Chloroform & 3.2 & $\begin{array}{l}0.2-20 \\
0.2-5\end{array}$ & $\begin{array}{l}0.9963 \\
0.9992\end{array}$ & 53 & 0.024 & 0.2 \\
\hline Trichloroacetonitrile & 3.7 & $0.05-1$ & 0.9996 & 65 & 0.103 & 0.05 \\
\hline Bromodichloromethane & 4.2 & $0.2-5$ & 0.9982 & 64 & 0.033 & 0.05 \\
\hline Dichloroacetonitrile & 4.5 & $0.05-1$ & 0.9991 & 45 & 0.008 & 0.05 \\
\hline 1,1-Dichloro-2-propanone & 4.6 & $0.05-1$ & 0.9999 & 44 & 0.016 & 0.05 \\
\hline Trichloronitromethane & 5.5 & $0.05-1$ & 1.0000 & 69 & 0.104 & 0.05 \\
\hline Dibromochloromethane & 5.9 & $0.05-5$ & 0.9986 & 72 & 0.032 & 0.05 \\
\hline Bromochloroacetonitrile & 6.5 & $0.05-1$ & 0.999 & 71 & 0.017 & 0.05 \\
\hline 1,1,1-Trichloro-2-propanone & 6.8 & $0.05-0.5$ & 0.9998 & 84 & 0.035 & 0.05 \\
\hline Bromoform & 8.0 & $0.05-0.5$ & 0.9975 & 81 & 0.032 & 0.05 \\
\hline Dibromoacetontrile & 8.7 & $0.05-1$ & 0.9973 & 23 & 0.004 & 0.05 \\
\hline
\end{tabular}


Fig. 1 GC-XSD chromatogram of THMs $\left(40 \mu \mathrm{g} \mathrm{L}^{-1}\right)$ in Milli-Q water

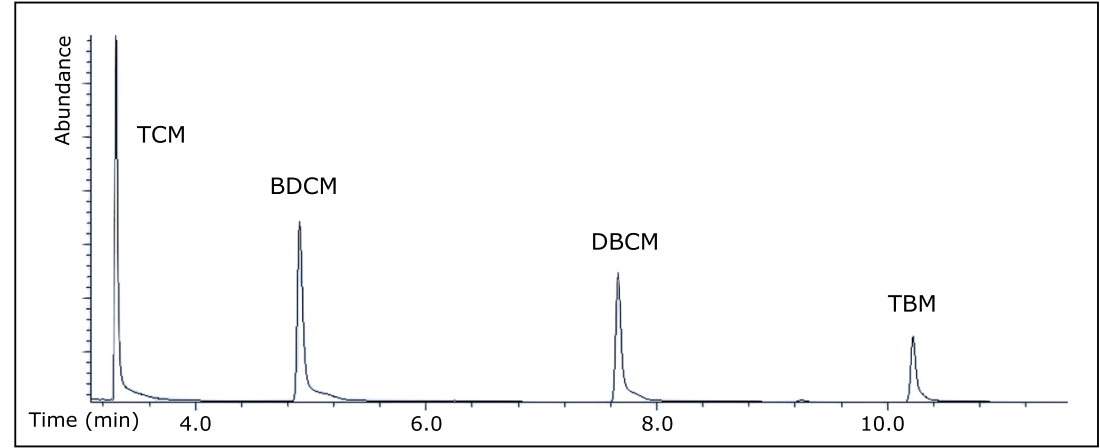

\section{Instruments}

Gas chromatography was performed on an Agilent 6890 interfaced to a 5973 mass spectrometer (MS) (Agilent Technologies, Avondale, PA, USA). The GC was also equipped with a detector system with a photoionization detector (PID) followed in tandem by an XSD (OI Analytical, College Station, TX, USA). The PID was not used for this work. Consequently, the PID will only be mentioned below when relevant for the discussion. Separation took place on a DB-5 column $(30 \mathrm{~m} \times 0.25 \mathrm{~mm}$ i.d. $\times 0.25-\mu \mathrm{m}$ film thickness, (J\&W Scientific Sacramento, Folsom, CA, USA), with the flow split 1:9 between the MS and the PID-XSD. The MS was operated with electron ionization at $70 \mathrm{eV}$ under full scan mode $(\mathrm{m} / z, 40-550)$. The GC inlet was operated in splitless mode with the oven temperature permitting solvent trapping of the analytes at the head of the column. The GC temperature program was $27^{\circ} \mathrm{C}$ held isothermally for $1.3 \mathrm{~min}, 7^{\circ} \mathrm{C} \mathrm{min}{ }^{-1}$ to $80^{\circ} \mathrm{C}$ followed by $30^{\circ} \mathrm{C} \mathrm{min}^{-1}$ to $250^{\circ} \mathrm{C}$, held isothermally for 5 min. PID sweep flow and XSD air flow were 30 and $30 \mathrm{~mL} \mathrm{~min}^{-1}$, respectively. Helium was used as carrier gas. The optimized conditions gave a good separation of the chromatographic peaks for the identification of the neutral DBPs. The analytes were identified from the retention times of the individual analytes established using the MS detector and by comparison of the mass spectral data of pure compounds with the NIST 2005 database and specific diagnostic ion fragments of each component.

\section{Quality assurance and control}

Standard operation procedures were adopted, following a strict method protocol ensuring consistency in method execution. Analytes were identified by comparing the retention time $( \pm 2 \%)$ with the corresponding standards. The surrogate standard (1,2-dibromopropane) was added to water samples and consistently used to calculate the recovery for extraction quality control. The recovery standard (1-chlorodecane) was added to the final extracts and was used for quantification of each analyte taking into account differences in chromatographic runs and extracted volumes. Calibration curves (4-6 points) were constructed in a concentration range described in Table 2, depending on the individual compound, see supplementary materials Tables S2-S4 for peak area data for target DBPs, surrogate standard, and recovery standard for both calibrations and water analysis.

The equipment was rinsed with methanol, and laboratory blanks were analyzed repeatedly to assess potential sample contamination. The extraction recoveries for each target DBP were determined by performing three extractions of Milli-Q water $(1 \mathrm{~L})$ spiked to $10 \mu \mathrm{g} \mathrm{L}^{-1}$ of each target DBPs. Because of the low noise of the detector, the limiting factor for this instrumental setup was the tailing of each peak (Figs. 1, 2, 3, and 4). Therefore, the limit of quantification (LOQ) was set equal to the concentration of the lowest standard concentration giving peaks that could be integrated. No further attempt was made to calculate the limit of detection
Fig. 2 GC-XSD chromatogram of an HAA standard (10 $\mathrm{ng} \mu \mathrm{L}^{-1}$ of each) in MtBE. TBAA is not visible here as it was almost entirely converted to TBM. The HAAs marked with asterisks are regulated in many countries

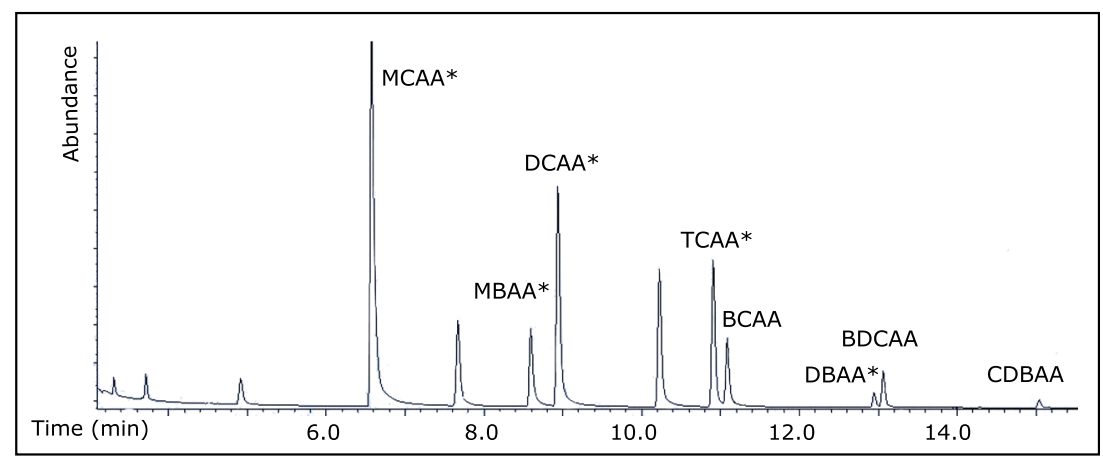


Fig. 3 GC-XSD chromatogram of neutral DBPs $\left(20 \mu \mathrm{g} \mathrm{L}^{-1}\right.$ of each) in Milli-Q water. The concentration of the internal standard (1,2-dibromopropane) was $50 \mu \mathrm{g} \mathrm{L}^{-1}$. The recovery standard (1-chlorodecane, $50 \mu \mathrm{g})$ was added to the sample vial just prior to injection

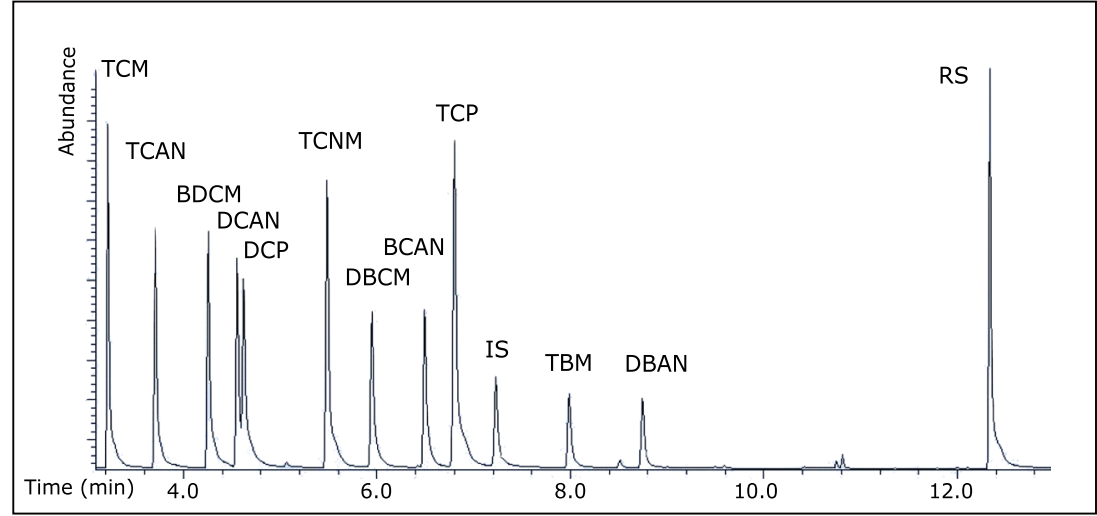

(LOD) of individual analytes. GC-XSD data was collected in MSD Chemstation D.03.00 and exported to Excel 2013 for further processing.

\section{Results and discussion}

\section{Method performance}

\section{Haloacetic acids}

Swedish work health regulations will not allow the use of diazomethane for routine laboratories. We, therefore, chose a derivatization method based on acidic methanol. The methyl esters of all the HAAs were detected with the XSD (Fig. 2), but the methylation efficiency differed between individual compounds affecting the overall recovery. In Fig. 2, the five HAAs (HAA5) that are regulated in some countries are marked with an asterisk (*), and among these, DBAA had the lowest response. It has been shown that methylation of the more sterically hindered HAAs, including TBAA, CDBAA, and BDCAA, are not complete even after $2 \mathrm{~h}$ of reaction with acidic methanol (Domino et al. 2003). Longer derivatization time did not enhance the derivatization efficiency. In addition to HAAs, peaks with retention times corresponding to THMs for the initial temperature program appeared in the chromatogram (Fig. 2). The MTBE blanks showed no presence of THMs, but HAA methyl esters may degrade into the corresponding THMs during gas chromatography (Heller-Grossman et al. 1993). The peak that appeared at retention time around 10.2 (Fig. 2) coincides with TBM indicating transformation of TBAA. The identity of TBM was also confirmed with GC-MS. Since unstable methyl esters were degraded to THMs giving false positive quantifications of THMs, simultaneous determination of THMs and HAAs should be avoided. In the further work, the method was optimized and evaluated for the measurements of neutral DBPs only.

\section{Neutral DBPs}

The neutral DBPs were well separated except for DCAN and DCP which co-eluted (Fig. 3). The temperature program was adjusted to optimize separation between DCAN and DCP, but they could not be fully separated in this GC system. The retention times, calibration ranges, correlation coefficients, extraction recoveries with standard deviations, and LOQs for each target DBP are shown in Table 2. The average extraction recovery was $63 \%$ with lower recoveries of analytes containing two halogen atoms than analytes containing three halogen
Fig. 4 GC-XSD chromatogram of DBPs in tap water from Berggården

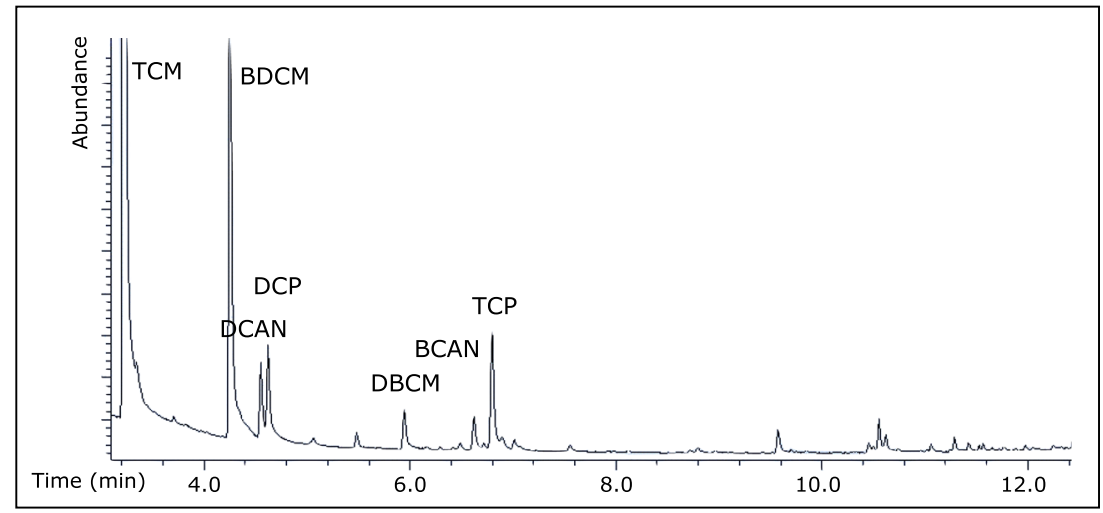




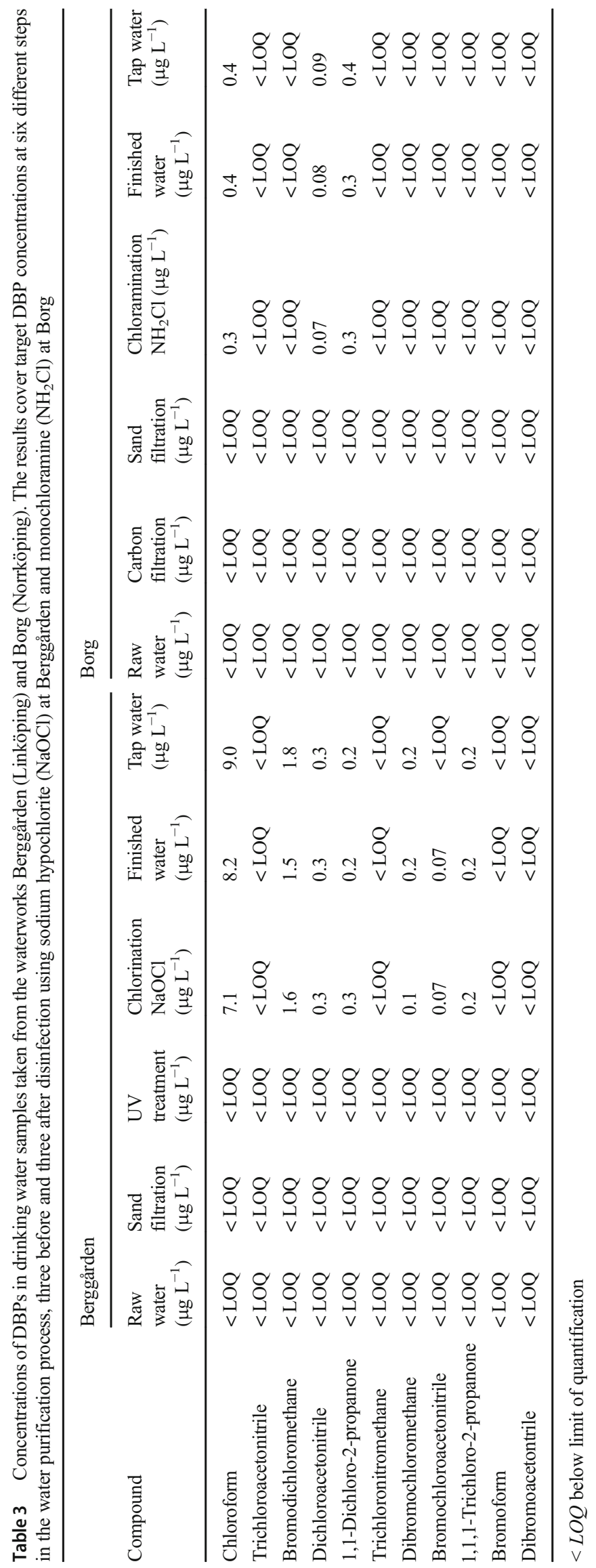


atoms. The LOQ determined for all the neutral DBPs was $0.05 \mu \mathrm{g} \mathrm{L}^{-1}$ except for chloroform that was $0.2 \mu \mathrm{g} \mathrm{L} \mathrm{L}^{-1}$. The LOQ for chloroform was higher than the other analytes, as trace levels of chloroform were present in the Milli-Q water blanks. Even though the detector has lower response for bromine than for chlorine, bromoform and dibromoacetonitrile were clearly detected at spiking concentrations of $0.05 \mu \mathrm{g} \mathrm{L}^{-1}$.

The linearity was tested by plotting the signal ratio of the analyte response and the recovery standard response on $Y$-axis versus concentration on $X$-axis. The correlation coefficients $\left(R^{2}\right)$ were above 0.99 for all target DBPs.

These calibration curves differed for different DBP compounds, as the detector response depends on the number of chlorine and bromine atoms in the compound. The calibration curves also varied due to systematic differences in extraction efficiency among compounds. Hence, one single surrogate standard cannot represent the extraction behavior of all the analytes studied. For this reason, the analyte to surrogate standard signal ratio was not used for quantification. The surrogate standard was instead used to control the extraction performance when analyzing real water samples.

The LOQ can be further decreased by extracting larger volumes or by optimizing the extraction conditions. Further, additional classes of toxicologically important DBPs can likely be determined simultaneously, given that they have similar characteristics in terms of extractability and volatility. One example of such a class is haloamides that might contribute to a major part of the DBP toxicity (Plewa et al. 2017; Wagner and Plewa 2017).

\section{XSD performance}

The XSD is highly selective for halogenated compounds, more so than the commonly used ECD (Nilsson et al. 2001). The response varies between different halogens and is higher for chlorine than for bromine. The high selectivity combined with the virtual absence of noise gave very clean chromatograms (Figs. 1, 2, 3, and 4), the stable baseline allowing detection of low concentrations. The start-up time of the detector to get a stable baseline was $30 \mathrm{~min}$. In this study, we focused on known DBPs of relevance to Swedish waterworks, but the high selectivity for halogenated compounds should also render the XSD useful for feedback between routine and research analysis. In other words, the XSD might be used as a tool to discover halogenated compounds that can be further investigated and identified with other methods.

The downside of this instrument setup was peak tailing in the XSD chromatograms. The tailing of the XSD peaks was observed for all compounds studied, but was absent in the MS chromatograms. Even when bypassing the splitter between the MS and PID-XSD tailing remained. Consequently, the tailing in our experiments was likely induced by the PID-XSD setup or the XSD itself. Testing a GC-XSD setup without a PID would be useful for further evaluation.

\section{Analysis of drinking water samples}

DBP concentrations were determined at different stages of the water treatment process in two waterworks, three before and three after the point of chlorination or chloramination (Table 3). The recoveries of the surrogate standard were within the acceptable range $70-130 \%$ for all samples at both waterworks. At Berggården, 7 out of the 11 neutral target DBPs were found and quantified in the water samples after chlorination. TCAN, TCNM, TBM, and DBAN were below the LOQ. The dominant DBPs at Berggården were TCM and BDCM with average concentrations of 8.1 and $1.6 \mu \mathrm{g} \mathrm{L}^{-1}$, respectively. The average total THM (sum of TCM, TBM, BDCM, and CDBM) were $9.9 \mu \mathrm{g} \mathrm{L}^{-1}$. Some DBPs were found at levels around $0.2 \mu \mathrm{g} \mathrm{L}^{-1}$ including DCAN, DCP, DBCM, and TCP. On the other hand, the dominant DBPs formed during chloramination at Borg were TCM and DCP, with average levels of 0.4 and $0.3 \mu \mathrm{g} \mathrm{L}{ }^{-1}$, respectively. DCAN was also detected at Borg, while the other target DBPs were below LOQ (Table 3). The total concentrations of THMs at Berggården and Borg were well under the limit $100 \mu \mathrm{g} \mathrm{L}^{-1}$ set by the Swedish Food Administration (Livsmedelsverket 2015).

A broad spectrum of neutral halogenated DBPs were successfully extracted from and detected in real-life samples using SPE coupled with GC-XSD. Figure 4 shows a GCXSD chromatogram of a tap water sample after distribution from Berggården. This demonstrates the selectivity of the XSD, which produces clean chromatograms even of real drinking water samples and allows successful determination not only of regulated DBPs but also of toxicologically relevant nitrogen containing DBPs not yet regulated.

\section{Conclusions}

With climate change, increasing population and decreasing access to clean water supplies, relevant control of DBPs will likely be an increasing public health concern. The work presented here is part of a larger project within which we aim to map DBP formation with ultra-high-resolution spectroscopic methods. Such methods will, however, not be possible to use for routine monitoring at waterworks. Part of the necessary vigilance for the future will have to be access to analytical methods that allow cheap and reliable determination of key DBPs. Our choice to test the XSD for this purpose was based on previous experience of its selectivity for halogens which enabled the analysis of chlorinated fatty acids where neither GC-ECD nor GC-MS gave sufficient selectivity or specificity for real samples. The GC-XSD setup is easy to operate and 
likely gives sufficiently high selectivity and specificity for routine DBP monitoring, but might also find its role in DBP research, where unknown halogenated compounds can be picked out with the XSD and further identified with other methods. Hence, the XSD may be used for routine monitoring, but it might also become a tool to identify future problematic DBPs.

Acknowledgements Mohammad Shoeb acknowledges the receipt of a visiting scientist grant from the Swedish Institute and funding from the International Programmes for Chemical Sciences, IPICS, Uppsala, Sweden. We also thank Lena Lundman and staff at Berggården and Borg waterworks for practical assistance.

Funding information Funding for this study was in part from the Swedish Research Council for Sustainable Development, FORMAS (grant no. 2013-1077).

Open Access This article is distributed under the terms of the Creative Commons Attribution 4.0 International License (http:// creativecommons.org/licenses/by/4.0/), which permits unrestricted use, distribution, and reproduction in any medium, provided you give appropriate credit to the original author(s) and the source, provide a link to the Creative Commons license, and indicate if changes were made.

\section{References}

Adams C, Timmons T, Seitz T, Lane J, Levotch S (2005) Trihalomethane and haloacetic acid disinfection by-products in full-scale drinking water systems. J Environ Eng 131(4):526-534. https://doi.org/10. 1061/(ASCE)0733-9372(2005)131:4(526)

Brown AN, Cook JM, Hammack WT, Stepp JS, Pelt JV, Gerard G (2011) Analysis of pesticides residues in fresh produce using buffered acetonitrile extraction and aminopropyl cleanup with gas chromatography/ triple quadrupole mass spectrometry, liquid chromatography/triple quadrupole mass spectrometry, gas chromatography/ion trap detector mass spectrometry, and GC with a halogen-specific detector. J AOAC Int 94(3):931-941

Bull RJ, Robinson M (1986) Carcinogenic activity of haloacetonitrile and haloacetone derivatives in the mouse skin and lung. Water Chlorination: Environmental Impact and Health Effects 5:221-227

Buszewski B, Szultka M (2012) Past, present, and future of solid phase extraction: a review. Crit Rev Anal Chem 42(3):198-213. https:// doi.org/10.1080/07373937.2011.645413

Cantor KP (1997) Drinking water and cancer. Cancer Causes Control 8(3):292-308. https://doi.org/10.1023/A:1018444902486

Cemeli E, Wagner ED, Anderson D, Richardson SD, Plewa MJ (2006) Modulation of the cytotoxicity and genotoxicity of the drinking water disinfection byproduct iodoacetic acid by suppressors of oxidative stress. Environ Sci Technol 40(6):1878-1883. https://doi.org/ $10.1021 / \mathrm{es} 051602 \mathrm{r}$

Chinn R, Lee T, Krasner S, Dale M, Richardson S, Pressman J, Speth T, Miltner R, Simmons JE (2007) Solid-phase extraction of $35 \mathrm{DBPs}$ with analysis by $\mathrm{GC} / \mathrm{ECD}$ and $\mathrm{GC} / \mathrm{MS}$. In: Proceedings of the American Water Works Association Water Quality Technology Conference. American Water Works Association, Denver

Ding S, Chu W (2017) Recent advances in the analysis of nitrogenous disinfection by-products. Trends Environ Anal Chem 14:19-27. https://doi.org/10.1016/j.teac.2017.04.001
Ding GY, Zhang XR (2009) A picture of polar iodinated disinfection byproducts in drinking water by (UPLC/)ESI-tqMS. Environ Sci Technol 43(24):9287-9293. https://doi.org/10.1021/es901821a

Dittmar T, Koch B, Hertkorn N, Kattner G (2008) A simple and efficient method for the solid-phase extraction of dissolved organic matter (SPE-DOM) from seawater. Limnol Oceanogr Methods 6(6):230 235. https://doi.org/10.4319/lom.2008.6.230

Domino M, Pepich B, Munch D, Fair P, Xie Y (2003) EPA Method 552.3, Revision 1.0: determination of haloacetic acids and Dalapon in drinking water by liquid-liquid microextraction, derivatization, and gas chromatography with electron capture detection. EPA/815/B-03/ 002 ,

EPA (2010) Stage 2 disinfectants and disinfection byproducts rule. Consecutive Systems Guidance Manual EPA 815-R-09-017

EU (1998) Council Directive 98/83/EC of 3 November 1998 on the quality of water intended for human consumption. Official journal of the European Communities L 330/32

Golfinopoulos SK, Nikolaou AD (2005) Survey of disinfection byproducts in drinking water in Athens, Greece. Desalination 176(13):13-24. https://doi.org/10.1016/j.desal.2004.10.029

Goslan EH, Krasner SW, Bower M, Rocks SA, Holmes P, Levy LS, Parsons SA (2009) A comparison of disinfection by-products found in chlorinated and chloraminated drinking waters in Scotland. Water Res 43(18):4698-4706. https://doi.org/10.1016/j.watres.2009.07. 029

Heller-Grossman L, Manka J, Limoni-Relis B, Rebhun M (1993) Formation and distribution of haloacetic acids, THM and TOX in chlorination of bromide-rich lake water. Water Res 27(8):13231331. https://doi.org/10.1016/0043-1354(93)90219-8

Hodgeson J, Cohen A, Munch D (1990) Determination of chlorination disinfection byproducts, chlorinated solvents, and halogenated pesticides/herbicides in drinking water by liquid-liquid extraction and gas chromatography with electron capture detection. Environmental Protection Agency, Cincinnati

Hodgeson J, Collins J, Barth R, Munch D, Munch J, Pawlecki A (1995) METHOD 552.2 determination of haloacetic acids and dalapon in drinking water by liquid-liquid extraction, derivatization and gas chromatography with electron capture detection Methods for the Determination of Organic Compounds in Drinking Water, Supplement III. US Environmental Protection Agency, Cincinnati

IARC (1995) IARC monograph on the evaluation of carcinoegenic risks to humans. Dry cleaning, some chlorinated solvents and other industrial chemicals, vol 63. International Agency for Research on Cancer, Lyon

IARC (1999) Monographs on the evaluation of carcinogenic risks to humans. Some chemicals that cause tumours of the kidney or urinary bladder in rodents and some other substances, vol 73. Lyon

Krasner SW, Weinberg HS, Richardson SD, Pastor SJ, Chinn R, Sclimenti MJ, Onstad GD, Thruston AD (2006) Occurrence of a new generation of disinfection byproducts. Environ Sci Technol 40(23):7175-7185. https://doi.org/10.1021/es060353j

Livsmedelsverket (2015) Livsmedelsverkets föreskrifter om dricksvatten, SLVFS 2001:30. http://www.livsmedelsverket.se/globalassets/omoss/lagstiftning/dricksvatten - naturl-mineralv—kallv/slvfs-200130-kons-2015-3-webb.pdf. Accessed 29 Sept 2017

Lovelock JE (1958) A sensitive detector for gas chromatography. J Chromatogr 1:35-46. https://doi.org/10.1016/S0021-9673(00) 93398-3

Nikolaou AD, Lekkas TD, Golfinopoulos SK, Kostopoulou MN (2002) Application of different analytical methods for determination of volatile chlorination by-products in drinking water. Talanta 56(4):717726. https://doi.org/10.1016/S0039-9140(01)00613-0

Nilsson GÅ (2004) Determination of chlorinated fatty acids using SPE, $\mathrm{XSD}$ and GC/MS with particular regard to cultured human cells. Dissertation, Swedish University of Agricultural Sciences, Uppsala 
Nilsson GÅ, Nilsson O, Odenbrand I, Wesén C (2001) New halogenspecific detector applied to the analysis of chlorinated fatty acids. $\mathrm{J}$ Chromatogr A 912(1):99-106. https://doi.org/10.1016/S00219673(01)00519-2

OI Analytical (2017) 5360/5360A XSD Halogen-specific detector. https://www.oico.com/5360XSD. Accessed 29 Sept 2017

Pavón JLP, Martín SH, Pinto CG, Cordero BM (2008) Determination of trihalomethanes in water samples: a review. Anal Chim Acta 629(12):6-23. https://doi.org/10.1016/j.aca.2008.09.042

Plewa MJ, Wagner ED, Muellner MG, Hsu K-M, Richardson SD (2008) Comparative mammalian cell toxicity of N-DBPs and C-DBPs. Urbana 51:61801

Plewa MJ, Wagner ED, Richardson SD (2017) TIC-Tox: a preliminary discussion on identifying the forcing agents of DBP-mediated toxicity of disinfected water. J Environ Sci (China). https://doi.org/10. 1016/j.jes.2017.04.014

Qian Y, Wu M, Wang W, Chen B, Zheng H, Krasner SW, Hrudey SE, Li XF (2015) Determination of 14 nitrosamines at nanogram per liter levels in drinking water. Anal Chem 87(2):1330-1336. https://doi. org/10.1021/ac504104k

Richardson SD (2010) Environmental mass spectrometry: emerging contaminants and current issues. Anal Chem 82(12):4742-4774. https:// doi.org/10.1021/ac101102d

Richardson SD (2011) Disinfection by-products: formation and occurrence in drinking water. Encycl Environ Health 2:1414-1422

Richardson SD, Postigo C (2015) Formation of DBPs: state of the science. In: Society AC (ed) Recent Advances in Disinfection Byproducts, vol 1190. ACS Symposium Series, Washington DC, pp 189-214

Richardson SD, Ternes TA (2005) Water analysis: emerging contaminants and current issues. Anal Chem 77(12):3807-3838. https:// doi.org/10.1021/ac058022x

Richardson SD, Plewa MJ, Wagner ED, Schoeny R, DeMarini DM (2007) Occurrence, genotoxicity, and carcinogenicity of regulated and emerging disinfection by-products in drinking water: a review and roadmap for research. Mutat Res 636(1-3):178-242. https://doi. org/10.1016/j.mrrev.2007.09.001

Sarrión M, Santos F, Galceran M (2000) In situ derivatization/solid-phase microextraction for the determination of haloacetic acids in water. Anal Chem 72(20):4865-4873. https://doi.org/10.1021/ac000479d

Tominaga MY, Mídio AF (2003) Comparison of two validated gaschromatographic methods for the determination of trihalomethanes in drinking water. Revista Brasileira de Ciências Farmacêuticas 39(2): 195-202. https://doi.org/10.1590/S 1516 93322003000200010

Villanueva CM, Cantor KP, Grimalt JO, Malats N, Silverman D, Tardon A, Garcia-Closas R, Serra C, Carrato A, Castano-Vinyals G, Marcos R, Rothman N, Real FX, Dosemeci M, Kogevinas M (2007) Bladder cancer and exposure to water disinfection by-products through ingestion, bathing, showering, and swimming in pools. Am J Epidemiol 165(2):148-156. https://doi.org/10.1093/aje/ kwj364

Villanueva CM, Cordier S, Font-Ribera L, Salas LA, Levallois P (2015) Overview of disinfection by-products and associated health effects. Curr Environ Health Rep 2(1):107-115. https://doi.org/10.1007/ s40572-014-0032-x

Wagner ED, Plewa MJ (2017) CHO cell cytotoxicity and genotoxicity analyses of disinfection by-products: an updated review. J Environ Sci (China) 58:64-76. https://doi.org/10.1016/j.jes.2017.04.021

Xie Y (2001) Analyzing haloacetic acids using gas chromatography/mass spectrometry. Water Res 35(6):1599-1602. https://doi.org/10.1016/ S0043-1354(00)00397-3

Zhao YL, Qin F, Boyd JM, Anichina J, Li XF (2010) Characterization and determination of chloro- and bromo-benzoquinones as new chlorination disinfection byproducts in drinking water. Anal Chem 82(11):4599-4605. https://doi.org/10.1021/ac100708u

Zhuang W, McKague AB, Reeve DW, Carey JH (2005) Evaluation of halogen-specific detector (XSDTM) for trace analysis of chlorinated fatty acids in fish. Instrum Sci Technol 33(4):481-507. https://doi. org/10.1081/CI-200066205 